\title{
INTENTION TO USE CONTRACEPTIVE METHODS AMONG WOMEN UNDERGOING COMPREHENSIVE ABORTION CARE (CAC) IN MATERNITY HOSPITAL KATHMANDU, NEPAL
}

\author{
Dr. Rubina Shrestha ${ }^{1}$, Pimsurang Taechaboonsermsak ${ }^{2}$, Sulkontha Siri ${ }^{3}$
}

\begin{abstract}
INTRODUCTION:

Unplanned and unwanted pregnancy is one of the leading causes of maternal mortality and morbidity and still continues despite availability of a range of modern and effective contraceptives. Comprehensive Abortion Care (CAC) is to provide safe, high quality services to women in an affordable and acceptable way. The study is intended to identify the proportion of the women who have intention to use contraceptive methods following CAC, in the future and to know the reason for current nonuse.
\end{abstract}

\section{MATERIAL AND METHODS:}

A descriptive cross-sectional study of women undergoing CAC in maternity hospital Kathmandu was conducted from $1^{\text {st }}$ February to $21^{\text {st }}$ February 2011. Different factors affecting Intention to use contraceptives following CAC and their association were identified and analyzed. SPSS statistical software was used to perform analysis.

\section{RESULTS:}

Following CAC $61.5 \%$ had an intention to use contraceptives, injectables being the most common method followed by IUCD and pills. Side effects were the main reason for stopping and not having an intention to use. There was a significant association between duration of marriage, current use of contraceptive methods, attitude towards contraceptive method, subjective norm and intention to use contraceptive methods.

\section{CONCLUSION:}

The acceptance of contraceptives can be increased by having positive attitude, providing sufficient information to avoid fear related to side effects.

KEYWORDS: Intention to use contraceptives, CAC, knowledge, attitude, subjective norm

1. Lecturer, Department of Community Medicine, Universal College of Medical Sciences

2. Assistant Professor, Department of Family Health, Mahidol University

3. Lecturer, Department of Biostatistics, Mahidol University

\author{
For Correspondence \\ Dr. Rubina Shrestha \\ Lecturer \\ Department of Community Medicine \\ Universal College of Medical Sciences, \\ Bhairahawa, Nepal \\ E-mail: rubinasht@hotmail.com
}




\section{INTRODUCTION}

Contraception is the use of artificial or natural means to prevent conception. About half of the unexpected pregnancies in developing countries are terminated, and WHO emphasizes the importance of providing family planning services after abortion. ${ }^{1}$ The goals of CAC program is to provide safe, high quality services to women in an affordable and acceptable way, thus to reduce the maternal mortality and morbidity. ${ }^{2}$ Though there is a compelling logic of preventing future unplanned pregnancy by post abortion contraceptives, still it remains' one of the weakest component of comprehensive abortion care $^{3}$.It is estimated that $120-150$ million married women worldwide wish either to have no more children or to delay their next birth at least two years but are not using any method ${ }^{4}$.

Every minute of every day at least one woman dies from complications of pregnancy and child birth, more than 585,000 deaths every year and $99 \%$ of these deaths occur in developing countries. Use of contraceptives can prevent at least $25 \%$ of all maternal deaths by preventing unintended pregnancies and unsafe abortions ${ }^{5 .}$ The decision about choosing and accepting contraceptives is likely to be influenced by various factors ranging from age, parity, age of youngest child, relationship with partner, influence of other person, knowledge, attitude and perception ${ }^{6}$.The study is intended to identify different factors which support the women to accept the methods as well as restrict them to accept it so that it can serve as base line information for further studies.

\section{MAERIALS AND METHODS}

This descriptive cross-sectional study was undertaken to assess the intention to use contraceptives, factors affecting intention to use contraceptives and to find the association between them and intention to use contraceptives among women undergoing CAC in maternity hospital Kathmandu, during $1^{\text {st }}$ February to $21^{\text {st }}$ February 2011.140 women within age group of 18-49 years with gestational age within 12 weeks who attend the $\mathrm{CAC}$ clinic during that period were included in the study and interviewed with the structured questionnaire ${ }^{5,7}$. Women who were not willing to participate, who attended the clinic for follow up and who had some complication were excluded.Statistical analysis was done by using (SPSS) 16.0. Chi-square test was used as an inferential statistics to analyze the association between the independent and a dependent variable. Statistical significance was accepted at the 5 percent level $(\mathrm{PV}$ Value $<0.05)$

\section{RESULTS}

In this study out of 140 women $37.1 \%$ who were married for 6 10 years and $53.6 \%$ of women who were using contraceptives before pregnancy had an intention to use the method following CAC.Both the variables were found to be significantly associated with intention to use contraceptive methods (Table 1)

Table 1. Descriptive statistics of General Characteristics $(n=140)$

\begin{tabular}{|c|c|}
\hline Variables & Percentage \\
\hline \multicolumn{2}{|l|}{ Age (years) } \\
\hline $18-29$ & 63.6 \\
\hline $30-39$ & 32.1 \\
\hline $40-49$ & 4.3 \\
\hline \multicolumn{2}{|l|}{ Marital Status } \\
\hline Married & 99.3 \\
\hline Single & 10.7 \\
\hline \multicolumn{2}{|l|}{ Duration of marriage } \\
\hline $6-10$ years & 37.1 \\
\hline$>10$ years & 35.0 \\
\hline $1-5$ years & 27.9 \\
\hline \multicolumn{2}{|l|}{ Level of education } \\
\hline No education & 21.4 \\
\hline Primary school & 21.4 \\
\hline Secondary level & 24.3 \\
\hline High school & 19.3 \\
\hline Bachelor degree \& higher & 13.6 \\
\hline \multicolumn{2}{|l|}{ Occupation } \\
\hline House wife & 51.4 \\
\hline Employee & 15 \\
\hline Business & 14.3 \\
\hline Farmer & 12.9 \\
\hline Labor/daily wages & 6.4 \\
\hline \multicolumn{2}{|l|}{ Family Income (rupees) } \\
\hline $10,000-15,000$ & 44.3 \\
\hline $5,000-9,000$ & 38.6 \\
\hline$>15,000$ & 17.1 \\
\hline \multicolumn{2}{|l|}{ Number of living child } \\
\hline $1-2$ & 70 \\
\hline$\geq 3$ & 20.7 \\
\hline No child & 9.3 \\
\hline \multicolumn{2}{|l|}{$\begin{array}{l}\text { Use of contraceptive before } \\
\text { pregnancy }\end{array}$} \\
\hline Yes & 53.6 \\
\hline No & 46.4 \\
\hline
\end{tabular}

Out of $53.6 \%$ women who were using at least one method of contraception, $40 \%$ were using condom, $29.3 \%$ of them were using oral pills, and $16.1 \%$ were usinginjectables. Among the nonusers of contraceptive methods, $58.6 \%$ stated that they left using it because of many side effects, while $20 \%$ said that they do not use it because their husband does not want them to use it. $61.5 \%$ intended to use contraceptive methods following CAC, out of these women $52.3 \%$ had intended to choose injectables as a choice of contraception. $80 \%$ of women who attended the clinic mentioned that unwanted pregnancy was 
the reason coming for abortion, while only $15 \%$ said that failure of contraceptive method was the reason.Similarlythe attitude and subjective norm about contraceptive methods was significantly associated with an intention to use contraceptives among women undergoing CAC. (Table 2)

Table 2. Association between Knowledge, attitude, subjective norm and perceived behavioral control \&intention to use contraceptive methods following CAC

\begin{tabular}{|c|c|c|c|c|c|}
\hline \multirow[t]{3}{*}{ Title } & \multicolumn{4}{|c|}{ Intention to use contraceptive method } & \multirow[t]{3}{*}{ P-Value } \\
\hline & \multicolumn{2}{|c|}{ Yes } & \multicolumn{2}{|c|}{ No } & \\
\hline & Number & Percent & Number & Percent & \\
\hline \multicolumn{6}{|c|}{ Level of knowledge about contraceptive method } \\
\hline Poor knowledge & 4 & 44.4 & 5 & 55.6 & 0.64 \\
\hline Fair Knowledge & 27 & 61.4 & 17 & 38.6 & \\
\hline Good knowledge & 50 & 57.5 & 37 & 42.5 & \\
\hline \multicolumn{6}{|c|}{ Level of knowledge about CAC } \\
\hline Poor knowledge & 25 & 55.6 & 20 & 44.4 & 0.704 \\
\hline Fair Knowledge & 56 & 58.9 & 39 & 41.1 & \\
\hline \multicolumn{6}{|l|}{ Level of attitude } \\
\hline Unfavorable & 7 & 25.9 & 20 & 74.1 & $<0.001$ \\
\hline Favorable & 74 & 65.5 & 39 & 34.5 & \\
\hline \multicolumn{6}{|c|}{ Levels of subjective norms } \\
\hline Low level & 31 & 39.7 & 47 & 60.3 & $<0.001$ \\
\hline High level & 50 & 80.6 & 12 & 19.4 & \\
\hline \multicolumn{6}{|c|}{ Level of perceived behavioral control } \\
\hline Low level & 13 & 48.1 & 14 & 51.9 & 0.255 \\
\hline High level & 68 & 60.2 & 45 & 39.8 & \\
\hline
\end{tabular}

"p-value by chi- square

\section{DISCUSSION}

Word intention here indicates the prospects of the women towards an intention to use contraceptives after the procedure. Out of $61.5 \%$ of the women who intended to use contraceptive following CAC, $52.3 \%$ had intention to take injectables as a choice of contraceptive to avoid unwanted pregnancy and repeated abortion. The acceptance rate of post-abortion contraceptive methods was high, $97.4 \%$ accepted at least one contraceptive method, and the most common method used was injectables,found in the studydone in Brazil. ${ }^{8}$ Similarly injectable was one of the popular method used following CACaccording to the study on improvement of the quality of CAC services in Nepal. ${ }^{9}$ Among those who did not have intention to use contraceptive methods following CAC, for more than half of them the reason was because of various side effects, some experienced in past, and some had strong belief and perception that it will create a lot of health problem.53.6\% of the respondents were using contraceptive methods with majority using condoms, pills and injectables respectively. Many of them said they left using injectables and oral pills because of the side effects leading to difficulties in their daily work, which changed their choice of contraception towards the use of condom. They also thought that IUCD and Implant insertion is difficult procedure and will create much more problems so they avoided using those contraceptive methods. This result is similar to the study done by SangiHaghpeykaret.el which explained that the side effects were the common cause of barrier to use contraceptive methods. ${ }^{10}$

There was a significant association between duration of marriage and intention to use contraceptives following CAC with ( $p$-value $=0.028)$. The study shows that with increase in duration of marriage the intention to use contraceptive methods tends to increase the reason being completion of family, similar to the study done in Philippines ${ }^{11}$.There was significant association between current use of contraceptive methods and intention to use it following CAC ( $\mathrm{p}$-value $=$ 0.009). Those who were currently using some method of contraception had an intention to use it after the procedure also. Many of them said that they did not want to use any method because of the side effects; at the same time those who were using it at present and had some side effects intended to change the choice of contraception and continue to use it, this result was similar to the studies done in Tehran and Malawi. ${ }^{12,13}$ The association between attitude towards contraception and intention to use contraceptives among women undergoing CAC (p-value $<0.001$ ) was found to be significant. $65.5 \%$ of them had a favorable attitude and had strong intention to use contraceptives; this attitude may be the reason for having an intention to use contraceptives. They agreed that unplanned pregnancy can cause financial burden for raising the baby and contraception is the choice to prevent this unwanted pregnancy, to regain their strength between two pregnancies by spacing child birth. While some agreed that side effects of contraceptives which hamper their health is the problem for using it leading them to have unfavorable attitude. This result is similar to the study in Malawi, reported that though there were family planning services available in the area; women do not use the modern family planning methods because of the negative attitudes, myths and beliefs. Reason included: perceived side effects, such as prolonged menstruation, men's concerns about impotence and genital sores, weight gain and subsequent infertility ${ }^{13}$. A significant association was there between subjective norms towards contraception and intention to use it ( $\mathrm{p}$-value $<0.001$ ). $80.6 \%$ with high level of subjective norm influence on contraceptive use had an intention to use contraceptive following CAC. Most of them agreed that their doctor and their partner and friends suggest them to use some method of contraception and their suggestion was very important for them. Various study have shown association with the subjective norm influence on 
contraceptive use like when women in Kenya were asked for the reason to use contraceptive methods, most cited the attitudes of their spouse or their peers, or other religion or values $^{14}$, according to the study conducted in Ethiopia, most women's contraceptive knowledge and practice was influenced by socio-cultural norms as husband dominance and low socioeconomic status of women ${ }^{15}$.

This study was a cross sectional study, sample was taken from CAC clinic of Maternity Hospital within the limited time. The sample was not representative of the general population of the country; it can only represent that population coming for abortion in CAC clinic. Hence, the results of the study may not be generalized. In this study only women with in the age group of 18-49 years were included. Study shows that the median age at first marriage among women age 25-49 is 17.5 years;with most of those bearing children in their teenage. ${ }^{16}$ Thus this study lacks those young age pregnant women who need to be considered, as teenage pregnancy is another raising problem in developing country like Nepal. So the future study including these age group and large sample size can be more helpful.

\section{CONCLUSION}

The study suggest that though the women coming to the CAC clinic had good knowledge on contraceptive methods their beliefs, attitude towards contraceptives and social pressure had strong influence on intention to use contraceptive. Therefore the result suggests a need for improving the positive attitude towards contraception. The strong step towards the behavioral change which includes the positive attitude towards the use of contraception with the help of strong counseling to relief the fear of side effects could increase the acceptance.

\section{REFERENCES}

1. World Health Organization: Department of reproductive health and research facts on induced abortion worldwide; 2007.

2. Ipas; What is woman-centered comprehensive abortion care?

3. Rash V, Yambesi F, Massawe S: Medium and longterm adherence to postabortion contraception among women having experiencedunsafe induced abortion in Dar es Salaam, Tanzania. BMC Pregnancy Childbirth 2008, 32:1-8.

4. WHO, Country health system profile, Nepal. [Online] Available from:(http://wwwsearo.who.int/LinkFiles/Nepal_Profile.pdf [Accessed on 2010, Nov 18].
5. Weldegerima B, Denekew A. Women's Knowledge, preferences, and practices af modern contraceptive methods in Woreta, Ethopia. Research in social and Administrative Pharmacy, 2008 Sep;4:(3):302-www.ncbi.nlm.nih.gov/pubmed/ 18794040 .

6. UNFPA : Contraceptive Method Mix (2001).

7. Nobili MP, Piergrossi S, Brusati V, Moja EA: The effect of patient-centered contraceptive counseling in women who undergo a voluntary termination of pregnancy. Patient Educ Couns 2007, 65(3):361-8.www.ncbi.nlm.nih.gov/pubmed $/ 17125957$.

8. Ferreira AL, Souza AI, Lima RA, Braga C. Choices on contraceptive methods in post-abortion family planning clinic in the northeast Brazil. Reprod Health. 2010; 7:5.

9. Population, Health and Development (PHD) Group, An Exploratory Study of Complications from CAC: Improvement of the Quality of Comprehensive Abortion Care (CAC) Services in Nepal : 2008

10. Hyman A, Kumar A. A woman-centered model for comprehensive abortion care. International Journal of Gynecology \& Obstetrics. 2004 Sep;86(3):409-10.

11. Jamie, J. G. Factors influencing Filipino couples' desired family size and contraceptive use in the Philippines. (2006).

12. Tehrani FR, Farahani FK, Hashemi MS. Factors influencing contraceptive use in Tehran. Family Practice, Apr 2001; 18(2): 204-8

13. Effie K. Chipeta, Wanangwa Chimwaza, Linda Kalilani-Phiri: Contraceptive Knowledge, Beliefs and Attitudes in Rural Malawi: Misinformation, Misbeliefs and Misperceptions; Center for Reproductive Health, College of Medicine, University of Malawi (2006).

14. Blonna R, Watter D. Health Counselling: A microskills Appraoch. Jones and Bartlett Publishers Inc; 2005.

15. David O: Socio-Cultural and Norms Factors Influencing Family Planning Choices Among Couples in Ibadan Metropolis, Nigeria; EuroJournals Publishing, Inc. 2008.

16. Nepal Demographic and Health Survey 2011. Ministry of Health and population, New ERA, Macro International Inc; 2012.437 . 